\title{
COMO AS CORTINAS VERDES PODEM MITIGAR OS IMPACTOS DE UMA ETE ÀS POPULAÇÕES RESIDENTES EM SEU ENTORNO.
}

\author{
HOW CAN THE GREEN CURTAINS MITIGATE THE IMPACTS OF A \\ WASTEWATER TREATMENT PLANT IN THE POPULATION LIVING IN THE \\ SURROUNDINGS.
}

\author{
Cleusa Nunes Martins \\ Arquiteta (cnmartins@sanepar.com.br) \\ Paulo Eduardo Sobreira Moraes \\ Doutorado em Engenharia Florestal pela UFPR, Brasil (2007) - \\ (paulomoraes@ufp.br).
}

\begin{abstract}
RESUMO
Os impactos ambientais gerados pelo processo de tratamento de esgoto geram passivos ambientais, principalmente a emissão de gases e odores pelas estações de tratamento de esgoto (ETEs). Isto causa o descontentamento da população de entorno que fica exposta a esses odores. Para minimizar estes impactos e melhorar a qualidade de vida das populações residentes nas cercanias, é necessário o controle dos mesmos. As cortinas vegetais são instrumentos que podem contribuir para a minimização deste problema. O objetivo deste trabalho é salientar a importância da implantação das cortinas verdes para melhorar a qualidade de vida das populações residentes nas cercanias de uma ETE, pois a utilização de barreiras vegetais como técnica para controle de odores é utilizada em diversas situações em todo o mundo.
\end{abstract}

Palavras chave: Estações de tratamento de esgoto, odores, cortinas verdes, população.

\begin{abstract}
The environmental impacts generated in the operation of wastewater treatment plants (WWTP) have been creating environmental liabilities, namely the emission of odoriferous gases by these plants. This brings about complaints of the population living in the neighborhood, exposed to the bad odors. In order to minimize these impacts and improve the quality of life of the population near the WWTP, it is necessary to take measures for controlling these emissions. The green curtains have shown to be a good solution for the problem. The aim of this work is to stress the importance of implementing green curtains
\end{abstract}


around the WWTPs, for the well-being of the population living nearby, since it is a technique that has been utilized in several situations worldwide.

Keywords: Sewage treatment plants, odor, green curtains, population.

\section{INTRODUÇÃO}

O saneamento básico melhorou muito a oferta de água tratada e afastou o esgoto de regiões densamente povoadas, mas por outro lado, gerou grandes passivos ambientais, com cargas expressivas de esgoto, sem tratamento, lançados aos rios, e esses impactos ambientais também afetam a qualidade da água dos nossos mananciais.

Além da água e do esgoto, há também a emissão de gases e odores. A emissão de odores por estações de tratamento de esgoto tem gerado o descontentamento da população.Este problema vem se agravando, pois em decorrência do aumento da população, aumenta também o número de estações de tratamento de esgoto.Estas devem levar em conta técnicas para o controle de odores.

Mesmo sendo construídas em lugares afastados, com o aumento das cidades, as áreas ao redor vão sendo ocupadas, sem manter a adequada distância. Em consequiência disto, a população fica exposta a odores vindos destas estações.

As cortinas vegetais são instrumentos que podem contribuir para a minimização dos odores gerados pelos processos de tratamento das estações. Sua implantação deve ser antecipada, e pode ser anterior a implantação das obras civis nas ETEs.

As cortinas verdes também podem ser utilizadas para outras finalidades: proteção e barreiras de áreas, quebra-ventos, na agricultura e pecuária.

Neste caso, temos que levar em conta também a barreira natural que as cortinas verdes fazem, ao impedir também o acesso de animais e crianças às ETEs, evitando assim inúmeros acidentes e até mortes.

Para a implantação das cortinas verdes deve-se levar em conta as espécies de cada região, adaptando-as a características semelhantes. Deve-se levar em conta também a tipologia do solo e o regime hídrico do solo. 
Há também, para a implantação das cortinas vegetais a necessidade das atividades de manejo: roçadas, podas, adulação e reposição das plantas que não sobreviveram.

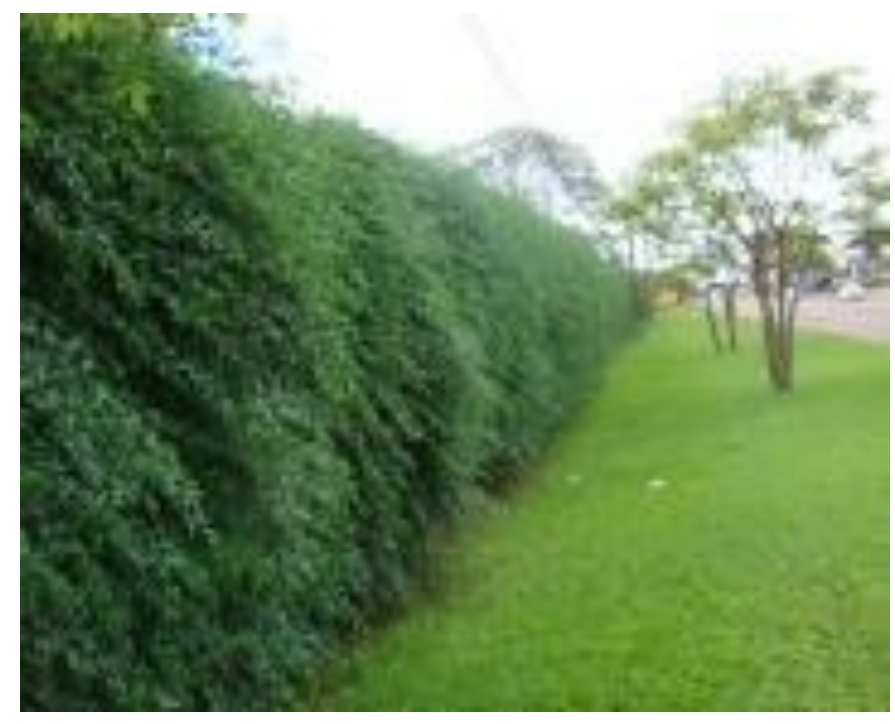

Fig.01: Modelo de cerca viva.

As populações de entorno das ETEs sofrem com as conseqüências desta proximidade. Além dos odores emitidos, também a insegurança com a facilidade de acesso às mesmas, podendo ser invadidas por animais e crianças, o que pode ser extremamente perigoso.

As cortinas vegetais são uma alternativa técnica como um instrumento que pode contribuir para minimização dos odores gerados pelos processos de tratamento nas estações. Elas são barreiras vegetais como técnica para controle de odores e são utilizadas em diversas situações em todo mundo, também como:quebra-ventos, cercas-vivas, ornamentação, proteção aos inimigos naturais das pragas, produção de néctar e pólen para as abelhas, abrigo para a fauna silvestre, embelezamento da propriedade, conservação das construções e locais de trabalho (diminuição de gastos com pinturas e danos ocasionais nas estruturas: telhados, por exemplo).O barulho e a poeira, bem como os ventos frios quando evitados proporcionam melhores condições de trabalho (LEAL, A C., 1986). 


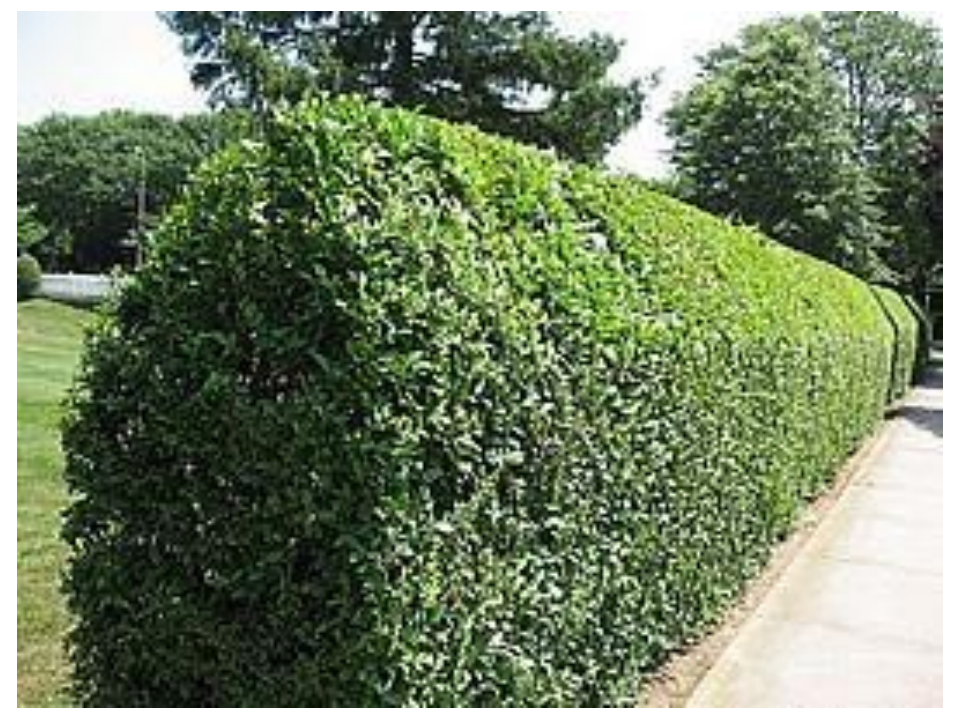

Fig.02: Modelo de cerca viva utilizada na ornamentação (paisagismo).

Devem ser consideradas as técnicas e os diferentes padrões vegetais, como também a observação das características do meio físico.

Ela se caracteriza pela implantação orientada de indivíduos de duas ou mais espécies arbóreas e arbustivas adaptadas à região e ao solo, distribuídos em linhas paralelas, de forma que as plantas de uma linha não fiquem alinhadas com as plantas da linha adjacente, formando barreiras de isolamento, as quais em ETEs são dispostas ao redor das fontes emissoras de odores e no seu entorno (CARNEIRO, SCHEER, CUNHA, ANDREOLI, 2009, p17).

Além da função de reduzir os odores emitidos pelas ETEs, essa vegetação também contribui muito para o fator estético e de segurança, promovendo o isolamento visual e físico da estação e melhorando a convivência com a população circunvizinha e também tornam o local mais agradável aos trabalhadores e freqüentadores.

O crescimento da população, em todo o mundo tem reduzido a distância que separa áreas residenciais e de fontes de odor. O aborrecimento pode resultar em não apenas os odores desagradáveis como também prolongados odores agradáveis, tais como produzido por uma fábrica de chocolate ou de fritura. 
Odores indiretamente afetam a saúde humana através de estresse (Evans \& Cohen, 1987) e seu impacto é maior quando os seres humanos são expostos a uma contínua e intermitente fonte. As pessoas com este tipo de problema (buscando resolver o problema do odor) podem tornar-se mais irritadas por odores do que aqueles que utilizam a cognição reconfortante (dizendo-se que a situação irá melhorar) ou ter um estilo emocional orientado (aqueles que procuram um desvio), porque a solução é muitas vezes fora de mão (Cavalini et al., 1991). Apesar de agradável os odores podem tornar-se irritantes quando muito concentrados ou persistentes, mau cheiros são percebidos como desagradáveis na maioria senão em todas as condições. Maus cheiros são também conhecidos para ativar uma área diferente do cérebro, em comparação com os odores agradáveis (Zald e Pardo, 2000). Segundo Jacob et al. (2003), a resposta dos seres humanos para mau cheiro é bastante consistente e difere comparada com a de odores agradáveis que produzem uma vasta gama de resposta.

Além disso, Jacob et al. (2003) descobriram que a detecção de qualquer odor aumenta com a dose e duração, mas que a mudança na resposta dos seres humanos é muito mais importante para pequenos aumentos nas concentrações de mau cheiro quando apresentados em um nível baixo apenas acima de seu limiar de detecção. Assim, modelos de dispersão de odor devem levar em consideração a resposta olfativa dos seres humanos. Odores nocivos são provavelmente muito mais fáceis porque a maioria dos humanos irá classificá-los como um aborrecimento, em oposição aos odores agradáveis em que a resposta é mais variável. Além disso, o sentido humano olfativo irá detectar a presença de um odor de um baixo nível e se nocivo, imediatamente classificá-lo como um incômodo. À medida que a concentração de ar do gás odorífero aumenta, o nível relativo de irritação não aumenta tão rapidamente. Além disso, a uma concentração de gás específico, a resposta torna-se intolerável e aumentando a concentração de qualquer outra não irá aumentar o nível de irritação. Para ser preciso, este tipo de resposta deve ser incorporado um modelo de dispersão de odor.

O uso de distâncias de separação ou revés para fontes de odor convenientemente assegura a diluição de mau cheiro para níveis aceitáveis nos arredores de vizinhos (Redwine \& Lacey, 2000). No entanto, as distâncias de separação convencionais dependem do odor generalizado independentemente das questões de gestão. Por conseguinte, distâncias de 
separação não fornecem legislação satisfatória contra incômodo em muitas instâncias (Jacobston et al., 2005). Distâncias de separação eficazes precisam considerar um maior número de fatores relativos à taxa de emissão de odor e caráter, e posterior dispersão antes de atingir os vizinhos. Além disso, práticas de gestão podem mudar a limpeza da operação, a frequiência e intensidade de emissão de odor e a localização da fonte na propriedade (Li \& Guo, 2008; Le et al, 2005; Lim et al 2001).

Fatores físicos e climáticos constituem outros fatores, a saber, topografia e edifícios, e estabilidade atmosférica, temperatura do ar e velocidade do vento e direção (Schauberger et al. 1999; Zhu et al. 2000; Lin et al, 2007c, 2009a, b).

Os florestamentos lineares ou em faixa, conhecidos genericamente como quebraventos arbóreos ou cortinas verdes, se destacam como uma prática que atende tanto às necessidades de proteção do meio ambiente, como de produção de matéria prima florestal. Os agricultores têm, desde tempos antigos, utilizado fileiras de árvores e arbustos vários, muretas, cercas, paliçadas, etc., para proteger as culturas do vento excessivo, sobretudo as vinhas, pomares, hortas e cultivos de flores. Mais recentemente, numerosas experiências realizadas em vários países demonstraram os efeitos dos quebra-ventos sobre os diversos fatores do clima, o que ampliou o campo de aplicação destas estruturas (PAVARI, 1961).

A importância dos quebra-ventos já foi reconhecida internacionalmente, como provam os numerosos experimentos realizados, e os grandiosos projetos de implantação executados em alguns países como EUA e Rússia, sobretudo em regiões com clima inóspito e topografia plana. Kosakawa e Farias (1985) chamam a atenção para o fato de que com sistema aerodinâmico de quebra-ventos é algo mais complexo do que "algumas fileiras" de árvores plantadas "esparsamente", e que quando implantados incorretamente podem minimizar os benefícios e aumentar os efeitos indesejáveis (LEAL, A C, 1986).

Os materiais utilizados nos quebra-ventos são os mais variados, desde barreiras mortas como cercas, paliçadas, esteiras, muretas, até as barreiras vivas formadas por fileiras de árvores e arbustos. Estas últimas são conhecidas como quebra-ventos arbóreos ou cortinas florestais (LEAL, A C., 1986). 


\section{OBJETIVO ESPECÍFICO}

As comunidades e o ambiente no qual as pessoas vivem, trabalham e desfrutam a vida vão continuar a estar em risco se criativas e eficazes soluções não forem propostas. Dependendo do projeto e das espécies arbustivas usadas, ele pode lidar com as mudanças do tempo, interceptação da pluma de odor durante todo o ano. Também está se tornando mais conhecida sobre como a estética da paisagem afeta a maneira como as pessoas podem perceber o odor de animais, sugerindo que a paisagem e elementos, tais como quebraventos podem levar a melhorias e opiniões talvez mais positivas.

Experiências recentes de túnel de vento em campos de estudos têm quantificado a eficiência da captação (Proporção de partículas batendo e sendo retidos pelas superfícies de árvores para a quantidade de partículas no ar) de várias espécies de árvores diferentes, bem como em condições de partículas totais de diferentes cargas (Beckett et al, 2000a.).

Outro fator que influencia a captura de partículas é uma rugosidade de árvores em grande escala, conforme definido pela estrutura do dossel total de árvores individuais ou agrupamento de árvores. A copa de alta complexidade (isto é, a estrutura pinada de cinzas (Fraxinus spp.) cria mais oportunidade para a obstrução do vento através do fluxo e, portanto, mais turbulência interna (Beckett et al, 2000a.). Curiosamente, foi observado, que quanto mais jovens, árvores de espécies menores que tem eficientes filtros de partículas também são altamente eficazes na remoção de partículas devido à sua maior densidade de vegetação em comparação com uma espécie muito maior, e espécies mais maduras (Beckett et al. 2000a). É difícil obter uma compreensão apenas da quantidade de acúmulo de partículas da matéria. Deve também ser enfatizado que o cálculo da capacidade real, ou cargas de partículas totais em árvores individuais ou agrupamento de árvores é confundida pelas condições ambientais.

- Quanto maior a rugosidade da superfície da folha, maior a eficiência de captura de partículas. A rugosidade da superfície aumenta com a presença de pêlos de folhas e venação (nervação), pronunciado. 
- folhas menores são geralmente mais eficientes que as folhas maiores na coleta de partículas.

- Folhas com formas complexas e grandes circunferências (ou seja, coníferas) parecem captar partículas mais eficientemente.

- As coníferas são geralmente mais eficientes na captura de partículas do que as espécies folhosas.

- Superfícies não laminares (pecíolos, caules, cascas) também acumulam quantidades signifi-cativas de partículas.

- Quanto mais irregular em forma de partículas são, ha maior captura de retenção da superfície da árvore.

Apesar da promessa de quebra-ventos como benéfica tecnologia, há alguns potenciais inconvenientes que são comuns às tecnologias baseadas em árvores.Há o tempo necessário para a vegetação crescer. Esta é uma desvantagem tecnológica difícil quando se lida com problemas de odor agudo e tendo que adaptar o tipo de vegetação.

É provável que as árvores precisem de pelo menos 3-5 anos de maturidade antes que quaisquer benefícios visíveis ocorram (embora esteticamente, os benefícios podem ocorrer mais cedo). Cortinas verdes também precisam de espaço.

Além da função de reduzir os odores emitidos pelas ETES, essa vegetação também contribui muito para o fator estético e de segurança, promovendo o isolamento visual e físico da estação e melhorando a convivência com a população circunvizinha e também tornam o local mais agradável aos trabalhadores.

\section{REFERENCIAL TEÓRICO}

HISTÓRICO DA EVOLUÇÃO DAS CORTINAS VERDES. 
Antes dos obstáculos de arame farpado, existiam outras formas de fortificações defensivas, como por exemplo, o abatis ou abatida, que era muito utilizado em fortificações defensivas primitivas para designar um obstáculo formado por galhos de árvores, abatidas, por em fileiras, em que suas pontas são direcionadas para o inimigo. .Existem abatises em que os galhos são entrelaçados por arames e normalmente eram utilizados em conjunto com outros obstáculos.Embora utilizados desde os tempos do império romano, os abatises rara- mente são vistos hoje em dia, tendo sido substituídos pelos obstáculos de arame farpado, mas quando o suprimento de arame é escasso, os abatises podem ser usados como alternativa.Abatis formados por grandes árvores inteiras podem ser usados como uma defesa anti-tanque improvisada.Outros exemplos eram utilizados, como obras de defesa primitiva, como paliçadas (conjunto de estacas de madeira fincadas verticalmente no terreno, ligados entre si, de modo a formarem uma estrutura firme).

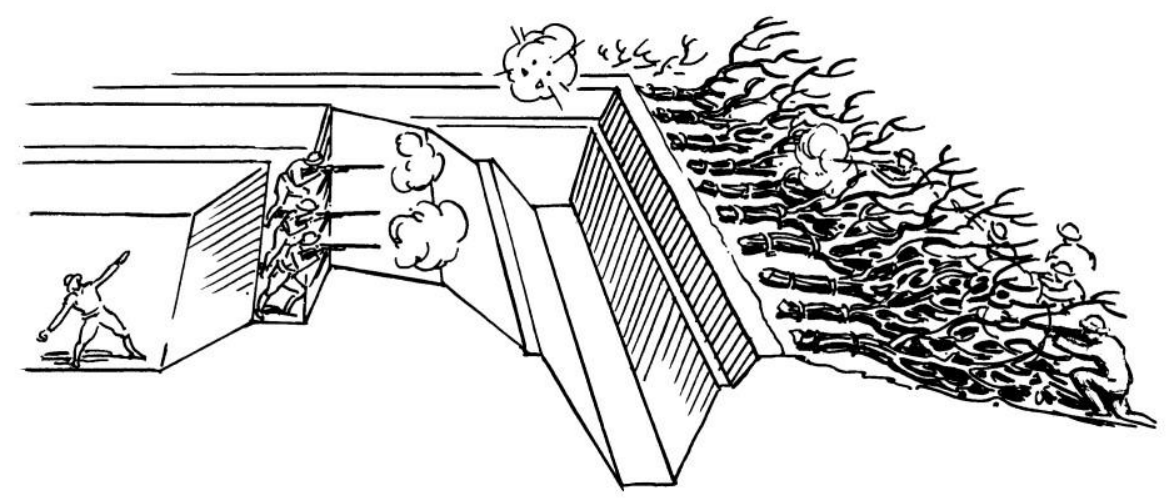

Fig.03: Uso de abatis na arquitetura militar primitiva. 


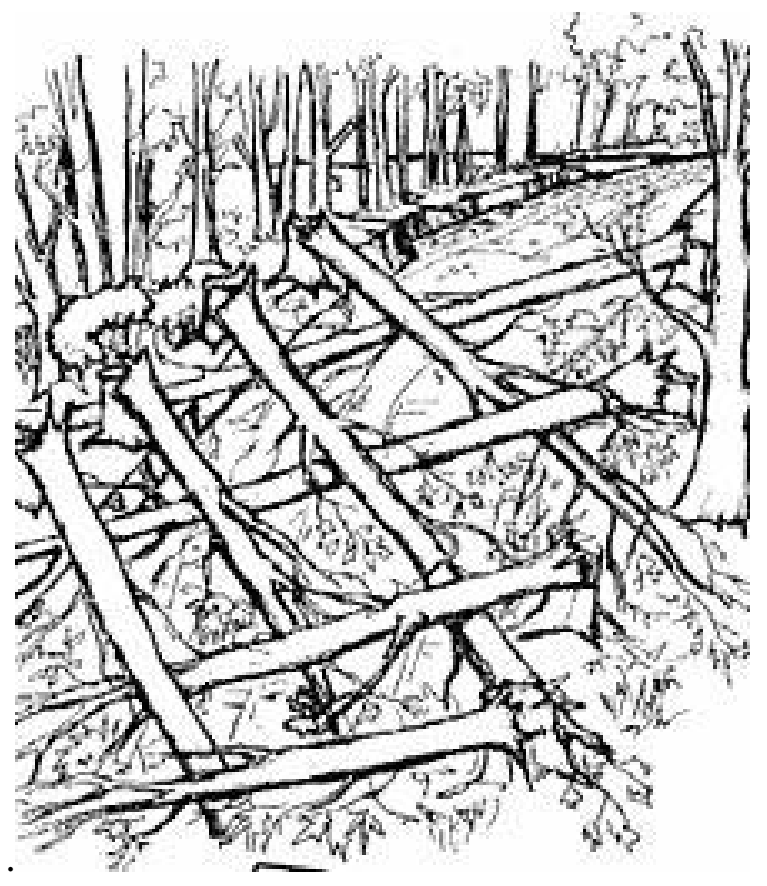

Fig. 04: Uso de abatis gigantes na arquitetura militar primitiva.

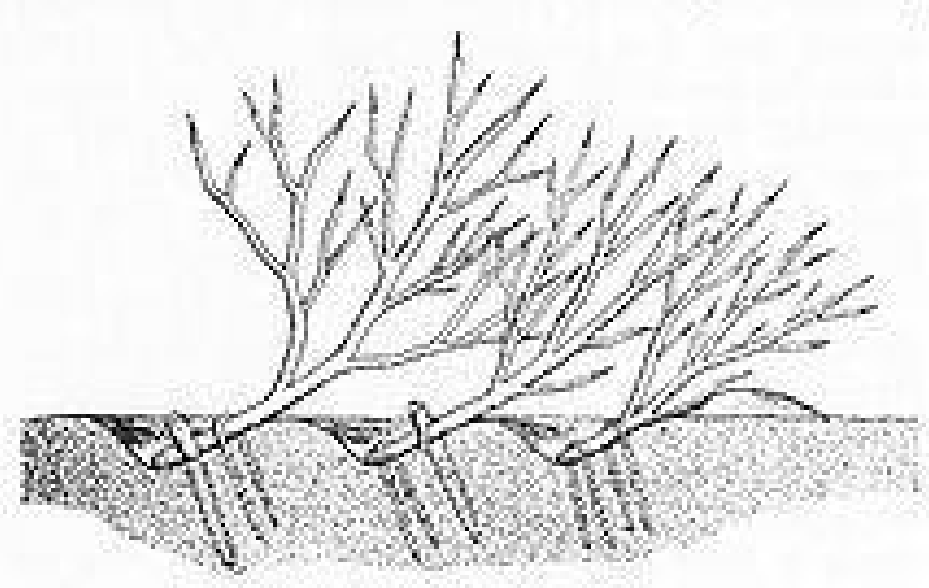

Fig.05: Uso de abatis improvisados por tropas japonesas. 


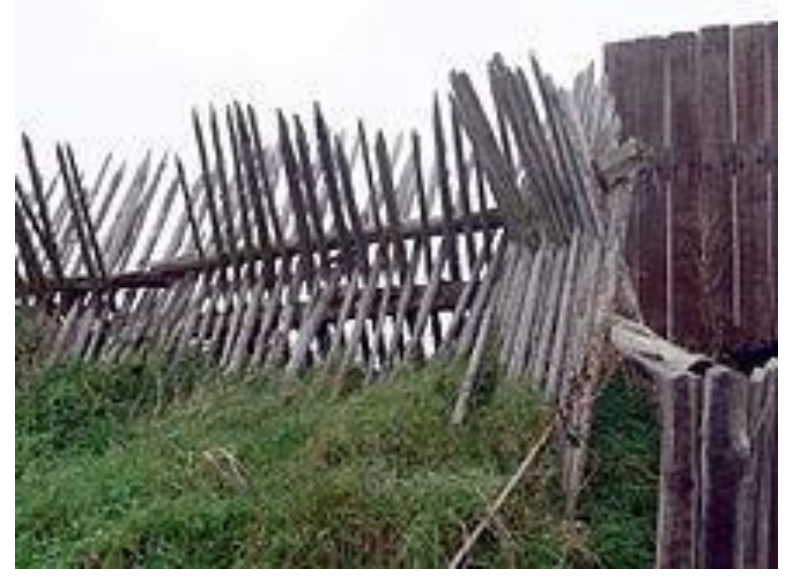

Fig.06: Uso de paliçada na arquitetura militar medieval.

$\mathrm{Na}$ arquitetura militar moderna, houve como exemplo, o "ouriço tcheco", que é um tipo de obstáculo anticarros utilizado em fortificações modernas, desenvolvido pouco antes da segunda guerra mundial e nela empregado por vários contendores. Consiste em três perfis de aço, com secções em forma de L ou H. Cruzados e unidos entre si.A sua designação deve-se ao seu formato, cujos espigões lembram os picos de um ouriço e ao seu país de origem.

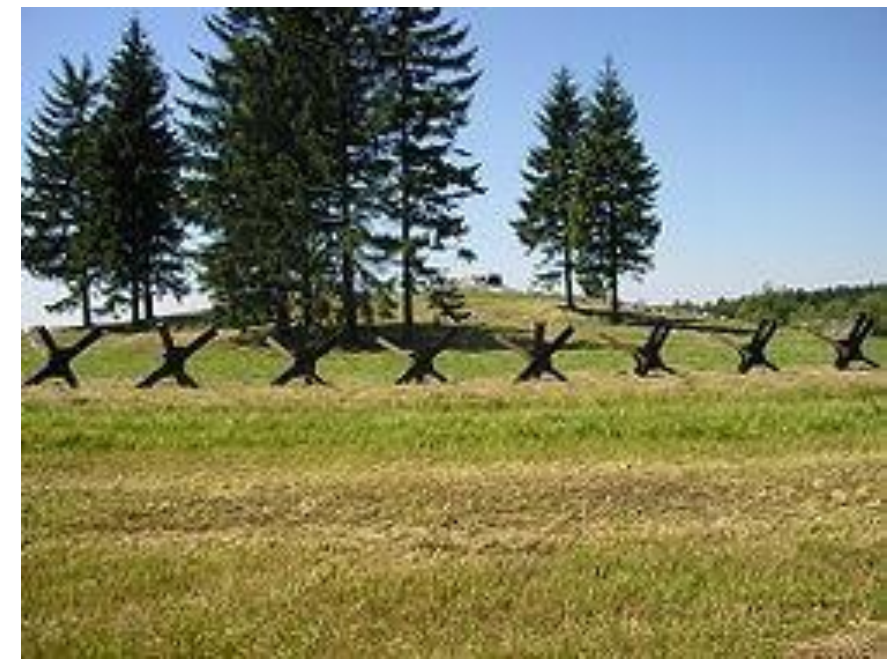

Fig.07: Ouriço checo na Polônia. Uso na arquitetura militar moderna. 


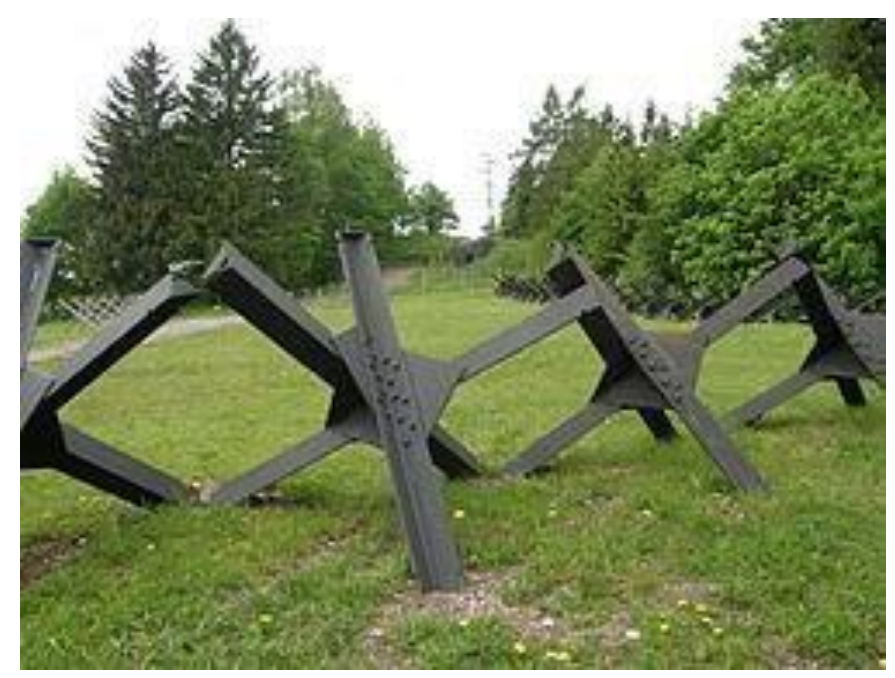

Fig.08: Uso de ouriço checo na antiga fronteira entre a Checoslováquia e Alemanha.

Já o arame farpado é um material produzido especialmente para a construção de cercas para deter animais, principalmente animais domesticados como o gado vacuum, mas também para restringir o movimento de pessoas.

Antes da comercialização do arame farpado, as chamadas cercas-vivas eram muito utilizadas para impedir que animais domésticos de porte médio e grande vagassem por onde quer que fossem nos Estados Unidos (com exceção às suas vastas regiões de latifúndios, como no estado do Texas, onde os caubóis mantinham controladas as grandes manadas de gado desde o lombo de seus cavalos). Vale notar que a construção de muralhas de pedra, como era feito na Velha Europa, geralmente não era algo visível na América do Norte e mesmo as cercas construídas com toras de madeira eram demasiado custosas financeiramente para os pioneiros do novo país. Assim, as cercas-vivas tornaram-se por muito tempo o método mais eficaz de desenvolvimento pastoral.

A planta que se tornou favorita no desenvolvimento dessas cercas-vivas foi a laranjeira-de- osage ou o pau-d'arco, uma árvore de pequeno-médio porte, nativa da América do Norte, com seus galhos agressivamente espinhentos, que passou a ser plantada em fileirões ao longo das divisas de propriedades rurais. Adicionalmente a larangeira-deosage possui uma madeira de excelente qualidade e que serve para múltiplos usos em sua madurez (i.e. cabos de ferramentas, arcos para a caça e esporte, instrumentos musicais, etc.). 
Atualmente (em 2007) essas cercas-vivas ainda podem ser vistas em boa parte da região central e sul dos Estados Unidos, mesmo suplantadas pelas cercas de arame farpado, mas, aos poucos, a laranjeira-de-osage está tornando-se uma planta ornamental.

$\mathrm{O}$ arame farpado é também símbolo das guerras de fileira e teve aplicações militares que remontam a 1888, quando os militares britânicos o construíram manualmente. Atualmente, o arame farpado é usado para proteger instalações militares, prisionais ou particulares, assim como para estabelecer algumas fronteiras territoriais.

$\mathrm{O}$ arame farpado básico, brevemente descrito acima, foi inventado no estado de Illinois nos Estados Unidos em 1873 e foi patenteado no ano de 1874 (em inglês: 'barbed wire' ou 'barbwire'). Hoje em dia, mais de cem anos desde a sua invenção, este produto é utilizado no mundo inteiro, sendo que existem vários tipos diferentes de arame farpado.

Glidden com seu sócio, Isaac Leonard Ellwood, fundou a Barb Fence Company, em De Kalb, e em pouco tempo o arame farpado tornar-se-ia comum em todo o oeste americano acelerando o desenvolvimento em toda a região com o crescimento da criação de gado.

Em 1876, Glidden vendeu sua metade da patente a Washburn \& Moen Manufacturing Companhia por US\$ 60.000 e os royalties. Com esse negócio, e investimentos em propriedades, tornou-o um dos homens mais ricos dos Estados Unidos.

A necessidade de racionalizar o uso dos recursos naturais exige um melhor aproveitamento dos agroecossistemas (GLIESSMAN,2001;ALTIERI,2002).Neste caso, a identificação de espécies de usos múltiplos, que cumpram objetivos sócio-econômicos e ecológicos é fator de suma importância para a sustentabilidade dos sistemas de produção.

O plantio de leguminosas arbóreas para serem usadas como moirões vivos na construção de cercas, apresentava-se como uma alternativa promissora para reduzir os efeitos supressivos causados ao ambiente através da aplicação dos meios convencionais de construção de cercas, constituindo um conjunto de ações importantes para a busca do desenvolvimento sustentável em propriedades rurais (FRANCO, 1988).

Leguminosas arbóreas bem estabelecidas podem fixar até $600 \mathrm{~kg}$ há-1 ano de $\mathrm{N}$ atmosférico nos tecidos vegetais (DÖBEREINER, 1984). A Gliricidia sepium (gliricídia), espécies do gênero Erythrina e outras espécies de leguminosas arbóreas capazes de fixar nitrogênio, vêm sendo alvo das atenções de muitos centros de pesquisas tropicais, em função da multiplicidade de produtos e benefícios que oferecem, além da grande 
adaptabilidade a diferentes zonas ecológicas.(NATIONAL ACADEMY OF SCIENCES,1980).

A cerca ecológica refere-se ao aproveitamento da estrutura formada a partir da disposição de espécies vegetais de ocorrência natural ou plantadas, de forma justaposta ou em linha, formando barreiras vivas, renques, quebra-ventos, além da possibilidade de se utilizar o tronco das árvores como moirões vivos para suporte do arame, em demarcação de limites de áreas.

Assim, a definição das expressões "cerca viva ou ecológica" está associada ao fato de se plantar ou manter os arbustos e árvores, ao invés de cortá-las.

Em termos gerais, oferece muito mais vantagem do que as cercas convencionais, tais como: custos de implantação mais baixos, maior durabilidade, geração de produtos econômicos, valorização da paisagem, proteção contra o vento, enriquecimento do solo serviços ambientais e outros (FRANCO et al. 1992; GLIESSMAN, 2001).

Quebra-ventos arbóreos são definidos (IBC, 1981) como barreiras constituídas de renques de árvores dispostos em direção perpendicular aos ventos dominantes.Essas barreiras são plantadas principalmente com a finalidade de reduzir a velocidade do vento e, assim, melhorar as condições ambientais para o desenvolvimento das culturas e para a pecuária.

Apesar dos primeiros quebra-ventos terem sido plantados na Escócia no século XVIII e terem se disseminado por toda a Europa e Ásia ainda no século XIX (GULOT, 1963) no Brasil eles começaram a surgir apenas neste século, na década de 70, seguindo a recomendação do IBC - Instituto Brasileiro do Café (BAGGIO, 1983).

Hoje podem ser vistas grandes áreas, especialmente de lavoura cafeeira no norte do Paraná, totalmente protegidas por quebra-ventos de Grevílea robusta.

Os quebra-ventos agem diretamente sobre o ambiente de três maneiras: sombreando parcial e temporariamente a cultura, absorvendo água e nutrientes do solo e diminuindo a velocidade do vento.

Em resumo, há uma redução nas perdas de água do solo por evapotranspiração, aumento da temperatura do ar e do solo durante o dia, redução nos danos causados pelo vento às culturas e controle da erosão eólica. Com o aumento da temperatura do ar e da capacidade de água disponível às plantas (CAD), há uma intensificação e maior duração do processo fotossintético, levando ao aumento da produção nas áreas protegidas. Estes efeitos 
se fazem sentir a partir de $2 \mathrm{H}$ (duas vezes a altura da barreira) até $30 \mathrm{H}$, segundo alguns autores (DURIGAN.;SIMÕES, I. W.1987).

No Brasil, as experiências dirigidas ao uso de cercas vivas buscam a racionalização e otimização dos sistemas produtivos, através da difusão do plantio e manejo de leguminosas arbóreas e do conjunto de benefícios que estas possam oferecer aos produtores rurais. Contudo, existe a necessidade de implementação de iniciativas que proporcionem o aumento da oferta de material vegetativo e identificação de outras espécies com potencial de uso como moirão vivo e construção das cercas ecológicas pode se tornar uma referência na orientação de ações que possam contribuir na elaboração e fortalecimento de políticas florestais. planeta.

A preservação do equilíbrio biológico é essencial para a sobrevivência do nosso

\section{CONCLUSÃO}

Podemos concluir através deste trabalho que a origem das barreiras de proteção no sentido histórico, como tendo sido, originalmente, para proteger contra o ataque de invasores dentro da arquitetura militar. $\mathrm{Na}$ arquitetura militar primitiva, eram utilizados muros, ou como estacas de madeira.Depois evoluíram com a junção da madeira com o ferro e depois (na segunda guerra mundial), obstáculos feitos de aço.A importância às cercas vivas, cortinas verdes ou barreiras vegetais foi dada na atualidade mais como função paisagística, em jardins de propriedades particulares ou públicas.

Atualmente, com a preocupação na minimização dos impactos ambientais, as barreiras vegetais assumiram um importante papel no controle de odores e são utilizadas também em diversas outras situações em todo o mundo, como por exemplo: contenção de particulados de pedreiras, a utilização de quebra-ventos na agricultura, na pecuária, áreas de lazer e a utilização da vegetação como forma de proteção dessas áreas, entre outras.

As estações de tratamento de esgoto estão localizadas em altitudes mais baixas e próximas a áreas urbanas. Isto pode causar aos habitantes no entorno um desconforto visual, estético, também pelo odor, afetando assim a saúde, em conseqüência de odores 
característicos que são produzidos durante o processo de tratamento do esgoto e dispersados pelos ventos a longas distâncias.

As reclamações sobre a emissão de odores por estações de tratamento e esgotos têm aumentado significativamente. Também se faz necessário o atendimento às novas exigências ambientais e em consequiência também do aumento da população nos conduz para a necessidade de construção de novas ETEs, especialmente nas regiões metropolitanas onde o crescimento da população é maior.

Com o crescimento das cidades, as proximidades foram sendo gradativamente ocupadas, e mesmo que as estações de tratamento de esgoto tivessem sido construídas em locais afastados, estas distâncias ficaram inadequadas, pois foram diminuindo pelo aumento da ocupação da população do entorno.

Este tipo de situação gera conflitos entre as empresas de saneamento e a comunidade.

\section{REFERÊNCIAS BIBLIOGRÁFICAS}

\section{CARNEIRO,Charles; BERGAMINI SCHEER,Maurício; CUNHA,Fabio;} ANDREOLI,Cleverson - Manual Técnico Para Implantação de Cortinas Verdes e Outros Padrões Vegetais em Estações de Tratamento de Esgoto-Curitiba-Sanepar, 2009. www.eps.ufsc.br/disserta97/pilotto/cap5.htm.Acesso em março 2012. www.vitruvius.com.br/revistas/read/arquitextos/12.133/3941.Acesso em março 2012. wikipedia.org/wiki/arame_farpado.Acesso em março 2012. wikipedia.org/wiki/abatis.Acesso em março 2012. www.cnpf.embrapa.br/pesquisa/efb/index_especies.htm.Acesso em março 2012. www.eps.ufsc.br/disserta97/pilotto/cap5.htm.Acesso em março 2012.

DURIGAN,G.;SIMÕES,J.W.1987.Quebra-ventos de Grevillea robusta a.Cunn - efeitos sobre a velocidade do vento, umidade do solo e produção do café.São Paulo - SP.IPEF 36:27-34.

LEAL, A C.1986. Quebra-ventos arbóreos:Aspectos fundamentais de uma técnica altamente promissora.Informe da Pesquisa.Fundação Instituto Agronômico do Paraná, Paraná, n.67,28p. 